\title{
La Globalización y los Nuevos Campos de Investigación en la Formación del Contador
}

Dra. Beatriz Herrera Garcia
Directora del Instituto de
Investigaciones de la Facultad de

Ciencias Contables

\section{INTRODUCCION}

I.1 Diagnóstico y problemática situacional

Uno de los problemas de las Facultades de Contaduría de América Latina, es disponer de un personal altamente calificado y capaz de dar respuesta a las nuevas situaciones que plantea la globalización de la economía y el nuevo orden económico nacional $e$ internacional, fundamentalmente, debido a una formación enteramente profesional como Contador Público-cuya eficiencia no se discute- y carente deldominio sólido de una preparación teórico-práctica sobre metodologias de investigación para abordar los nuevos temas de la realidad y adaptarse a la dinámica de los cambios socioeconómicos.

En el documento de"Reestructuración de los Planes de Estudio de la Maestría en Contaduría" de la UNAM (México, 15 de junio de 1994), se formulan un conjunto de propósitos para adecuarse a las nuevas corrientes académicas y llenar vacios anteriores; uno de ellos es orientar los planes de estudios a la formación de egresados capaces de enfrentar y resolver problemas globales y específicos; de realizar actividades que conduzcan a descubrir, crear e innovar el conocimiento. Los planes de estudios deben mantener un equilibrio y estar "orientados a la profundización del conocimiento y a la investigación". En suma, se resalta la importancia de la investigación como eje central de la educación, articulando, además, docencia e investigación para hacer frente al reto del desarrollo científico y tecnológico que la globalización impone.

Asimismo, en el documento "Reglas de Procedimiento y Temario" de la XXI CIC, se argumenta "el entorno de economía globalizada que día a día se intensifica en todos los países interamericanos, con el surgimiento de operaciones financieras y de intercambio comercial cada vez más sofisticadas.."(p. 43), para en una situación de cambio y globalización las investigaciones y en particular la investigación contable ocupe un lugar destacado en las discusiones de la Conferencia.

En sintesis las exigencias -en lo relativo a conocimientos y acción- que la reciente evolución económica y social plantea a la investigación y la formación en ciencias contables, se resume en la crisis de los paradigmas y en la incapacidad de la teoría convencional para ofrecer una explicación satisfactoria a los procesos en curso, nacionales y mundiales.

Se inicia el trabajo con un análisis acerca de la complejidad del proceso de la globalización y de los términos de las relaciones económicas, que han inducido a nuestros países a formas de integración o mundialización a partir de las desventajas de sus sistemas productivos. Definido ese contexto se intenta identificar los nuevos campos de investigación y la importancia de la política económica. 


\section{LA GLOBALIZACION Y EL DESARROLLO}

II.1 Mundialización de los procesos productivos y financieros

Durante mucho tiempo se ha considerado los flujos económicos como expresión monetaria directa de los flujos reales de producción e intercambio de bienes y servicios. Con Keynes, se reconoce que los flujos monetarios poseen su lógica propia y pueden incidir sobre los flujos reales. Este enfoque explica los desequilibrios de la economía nacional en términos de divergencias entre flujos reales y flujos monetarios. Sin embargo, en el plano internacional no se ha realizado un análisis de la combinación y de la divergencia entre ambos flujos.

Pero existen enfoques parciales que tratan con independencia los fenómenos monetarios y financieros, sobre el sistema monetario internacional; las transferencias internacionales de capitales; la transnacionalización de los bancos; los mercados financieros internacionales y la deuda externa. Asimismo, se enfocan con independencia los fenómenos reales sobre la inversión internacional; las empresas transnacionales; el comercio internacional, la división internacional del trabajo y las migraciones internacionales. Queda claro, por otro lado, que ambos factores parciales no ayudan en la comprensión completa de los procesos económicos que tienen lugar a escala internacional.

Las interelaciones, en el plano internacional, entre los fenómenos de producción e intercambio y los fenómenos monetarios y financieros parecen ser todavía más dignas de estudio por la preeminencia reciente de la lógica financiera sobrela lógica produc- tiva. La interpretación entre los bancos y las grandes empresas, $y$ el desarrollo acontecido en los años setenta del mercado del eurodólar, en conexión al gran aumento de excedentes financieros de los Países Exportadores de Petróleo, han determinado el volumen, la forma y la estructura de los intercambios internacionales de bienes y servicios, al igual que los procesos de industrialización en nuestros países.

Durantelas tres décadas transcurridas, la mayoría de los países latinoamericanos han vividocon un déficit crónico de su balanza de pagos (ver, Cuadro 1), compensado por flujos financieros provenientes de los países desarrollados, bajo forma de inversiones directas, de créditos públicos y privados, y de ayudas diversas. Entre finales de los años cincuenta y mediados de los ochenta, el nivel de consumo y de inversión dependió en parte de la disponibilidad de ingresos de transferencia. Es cierto que la existencia de transferencias netas positivas estuvo acompañada de transferencias implícitas de valor en sentido inverso, por el juego de intercambio desigual inherente al sistema de precios mundiales. Si se pudiera estimar el alcance de estas transferencias implícitas, el importede las transferencias netas positivas disminuiría muy sensiblemente, incluso se anularía. Las transferencias financieras visibles representaron de todos modos una forma visible de redistribución internacional de los ingresos en favor de nuestros países, cuyas implicaciones, al nivel del crecimiento tanto de los países receptores, han sido apenas estudiadas.

Desde mediados de los años ochenta, la reducción de operaciones de fondos privados (créditos e inversiones) y de ayudas públicas, asi como la agravación de la carga de la deuda externa (ver, Cuadros 2 y 3), invirtieron la dirección de las transferencias financieras netas en detrimento de Latinoamérica. Ahora bien, las implicaciones de estas transferencias para nuestras economías tampoco han sido analizadas. La deuda externa afecta al grado y las formas de integración de un país en el sistema económico mundial, en particular en la división internacional del trabajo. La mayoría de los préstamos concedidos estos últimos años por los bancos occidentales y japoneses favorecieron sobre todo a proyectos para los cuales la demanda previsible de los países desarrollados determinaba perspectivas de rentabilidad en divisas, es decir, de exportación. Los contactos que mantenían los grandes bancos y las grandes empresas transnacionales contribuyeron también a someter el crédito internacional a estrategias de dislocación industrial. Por otra parte, el servicio de la deuda externa (ver, Cuadro3) mantiene la necesidad de aumentar las exportaciones tradicionales de productos primarios y de crear otros nuevos, fundadas en la disponibilidad relativa de materias primas y energía o mano de obra barata.

Sin embargo, pasado cierto punto de endeudamiento, esta lógica de reajuste de los niveles de actividad productiva en función de las exigencias del orden financiero internacional se enfrentaba a limitaciones considerables. La magnitud de la deuda externa es tal en la mayoría de nuestros países que, por un lado, los créditos a la inversión han sido suspendidos por los bancos $y$, por otro lado, el servicio de la deuda supera con mucho el potencial del crecimiento de las exportaciones. La amortización de la deuda depende en lo sucesivo de un nuevo endeudamiento logrado mediante una larga y cos- 
Cuadro 1

Balanza de Pagos en Cuenta Corriente

(Millones de dólares)

\begin{tabular}{lrrrrrrrr}
\hline & 1986 & 1987 & 1988 & 1989 & 1990 & 1991 & 1992 & 1993 \\
\hline México & -1.673 & 3.968 & -2.443 & -3.958 & -7.117 & -13.785 & -22.811 & -20.518 \\
Perú & -1.172 & -1.640 & -1.246 & 94 & -1.092 & -1.584 & -2.065 & -2.080 \\
América & & & & & & & & \\
Latina & -16.746 & -9.535 & -9.396 & -5.457 & -768 & -15.875 & -32.141 & -41.851 \\
\hline
\end{tabular}

Fuente - BID, Progreso Económico y Social en América Latina, 1994. p. 269

\section{Cuadro 2}

Deuda Externa Total Desembolsada

(Millones de dólares)

\begin{tabular}{lrrrrrr}
\hline & 1988 & 1989 & 1990 & 1991 & 1992 & \multicolumn{1}{c}{1993} \\
\hline México & 99.204 & 93.817 & 105.958 & 115.291 & 113.378 & 118.894 \\
Perú & 18.245 & 18.583 & 20.068 & 20.720 & 20.297 & 21.963 \\
América & 426.757 & 421.743 & 442.308 & 456.400 & 464.680 & 481.235 \\
\hline
\end{tabular}

Fuente.- BID, 1994. Op. cit.

tosa renegociación.

II.2 Principales modificaciones comerciales, financieras $y$ monetarias.

A partir de los años setenta se precipitó la crisis del sistema de cooperación establecido en la posguerra. En lo comercial se acentuaron las modalidades proteccionistas parancelarias en una regresión desde los principios multilaterales del GATT, hacia formas del bilateralismo basadas en reciprocidades específicas. En lo financiero las tasas internacionales de interés se han elevado permanentemente por encima de sus promedios históricos y fluctúan en repuesta a las políticas y coordinaciones monetarias delos países desarrollados. Los tipos de cambio se han tornado también fluctuantes desde principios de los años setenta, y sus movimientos -los de las principales monedas- modifican las competitividades relativas de los diferentes países o bloques de países.

II.2.1 El nuevo escenario: libertad multilateral y reciprocidad bilateral.

La reciente desregulación internacional en el campo monetario y financiero, ha tenido como contrapartida una creciente re- gulación en el campo del intercambio de productos (comercio administrado). Las fluctuaciones cambiarias, han contribuído a producir cambios en la competitividad relativa de los diferentes países, los que no pueden ser contrarrestados por el instrumento arancelarioy exigen aplicación de medidas específicas de protección o subsidio.

La expansión de este comercio administrado, también responde a la pérdida de complementariedad y creciente competitividad de las posiciones productivas de los países desarrollados y países de reciente industrialización. De un lado, las denominadas economías NICs compiten crecientemente con las economías de protección y subsidio vinculados a la política agrícola de Estados Unidos y la Unión Europea, han sidoutilizados hace décadas. Pero estas políticas del sector agrícola se inscriben ahora en un marco generalizado de proteccionismo pararancelario $\mathbf{y}$ dentro de nuevos principios que forman la lógica del comercio administrado. Puesto que el proteccionismo pararancelario se ha visto estimulado por el carácter altamente fluctuante de los tipos de cambio, el principio del libre cambio está siendo reemplazado por el de la reciprocidad bilateral, que se expresa con claridad en los códigos de comercio exterior de los países desarrollados.

II.2.2 Tasas de interés y tipos de cambios.

La elevación en las tasas de interés y la sobrevaluación del dólar contribuyeron por tres vías diferentes a derrumbar los precios de los productos básicos. En un primer momento contribuyeron al ciclo recesivo de 1981/82 que deprimió la demanda de estos productos. En otro momento, a lo largo de los años ochenta la permanente elevación de las tasas internacionales de interés por encima de sus niveles históricos aumentó el costo financiero de mantener existencias de productos básicos. El alza en las tasas internacionales de interés no sólo estimuló el lanzamiento al mercado de volúmenes de existencias previamente retenidas sino que además, encareció el financiamiento de existencias reguladoras, incluidas en lascláusulas económicas de varios acuerdos entre productores y consumidores. Por último, está el impacto del carácter fluctuante y la elevación permanente de las tasas internacionales de interés. Los países altamente endeudados y América Latina en especial (ver, Cuadro 3) vieron incrementarse desmesuradamente el servicio periódico de su deuda, y encararon medidas de ajuste que incluyeron devaluaciones de sus monedas nacionales y otras acciones tendientes a incrementar sus exportaciones. Deesta manera se promovieron sobreofertas que contribuyeron a deprimir los precios internacionales de los productos básicos.

De hecho, en términos reales las tasas de interés y los precios de los productos básicos se han movido en dirección opuesta, al menos en sus tendencias generales a lo largo de la década pasada. 
Esta correlación no es casual y se vincula con los esfuerzos que efectúan los países desarrollados para coordinar sus políticas monetarias y financieras. Por ejemplo, las autoridades económicas estadounidenses al explotar un patrón dólar-productos básicos, de manera que cuando el precio de los productos básicos se elevara en términos de dólares, buscan provocar la retracción monetaria y el incremento de las tasas de interés para corregir esas influencias. Como la iniciativa se adopta en una menguante de largo plazo en los precios de los productos mismos empiecen a elevarse, otro tanto harán la tasas de interés. Esta preocupación de la Junta de la Reserva Federal por los precios de lo productos básicos constituye un reconocimiento indirecto de que la inflación en los países desarrollados ha logrado ser controlada gracias -al menos en parte- al derrumbe de largo plazo de aquellos precios.

En cuanto a las fluctuaciones cambiarias, al modificar la competitividad relativa de las diferentes monedas, han influido sobre las formas pararancelarias del proteccionismo. La incertidumbre cambiaria dificulta la evaluación delas ventajas comparativas internacionales requeridas para los cálculos beneficio/costo en la determinación de nuevos proyectos de inversión en productos básicos.

Por otro lado, cuando el dólar se eleva, los exportadores de productos cotizados en dicha moneda -como es el caso de los latinoamericanos- deben reducir sus precios para no perder competitividad en aquellos países cuya moneda están cayendo frente al dólar. En resumen, tanto las tasas reales de interés como la sobrevaluación del dólar, tienden a deprimir los precios de los productos básicos exportados por nuestros países.

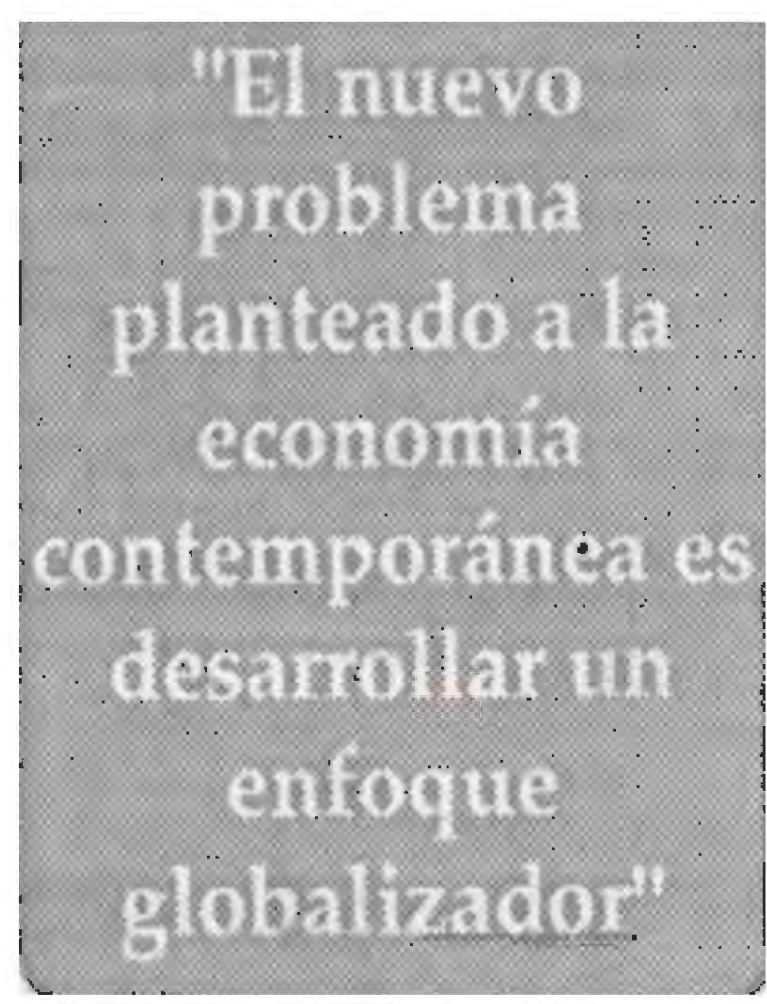

\section{II.2.3 El auge de los mercados de futuros}

En una perspectiva de corto plazo, los procesos de desregulación de los mercados que tanto favorecen el protagonismo de las transnacionales, también han estimulado el auge de los mercados de futuros $\mathrm{y}$, paralelamente con ellos, de la mayor volatilidad de los precios de los productos primarios. La existencia de las bolsas de productos básicos aunque antigua, debe su vertiginosa expansión actual a las relaciones financieras intenacionales cada vez más desreguladas, interdependientes y globales. Asi los precios de los productos básicos experimentan fluctuaciones frecuentemente asociadas a una especulación financiera basada en consideraciones mucho más amplias y complejas que las emanadas del mercado del producto en cuestión.

Una de las funciones de las bolsas de productos básicos ha sido, tradicionalmente, mitigar aquellas oscilaciones de precios a través de las actividades especulativas dealgunos operadores. En la medida que exista una firme expectativa sobre cual es el precio normal de largo plazo respecto del cual las variaciones cí- clicas fueran consideradas temporarias, entonces el comportamiento de los operadores ejercería una beneficiosa influencia anticíclica. Si los precios caen por debajo del normal de largo plazo, los operadores que especulan comprarán, acrecentando existencias retenidas y reduciendo la oferta, con lo que generarán tendencias alcistas, si los precios se elevan por encima del normal entonces los operadores venderían, para ganar la diferencia acrecentando la oferta y ejerciendo presiones bajistas.

Sin embargo, la variación internacional de las existencias retenidas depende de consideraciones ajenas, al menos en parte a la lógica de los operadores de las bolsas, basada en la oferta y demanda del producto respectivo. Hay otros elementos de juicio a tomar en cuenta derivados de los cambios en las reglas de jueg de la economía internacional, e especial, a partir de los años $s$ tenta.

Por ejemplo una perspectiv de inflación o una caída del dól puede reorientar recursos fina cieros del mercado monetari hacia el oro, la plata, u otros $\mathrm{m}$ tales más apreciados como reser va de valor bajo condiciones d extrema incertidumbr cambiaria. Esto puede produ bruscas variaciones en los pr cios de futuros. A la inversa u abrupta elevación de las tasas d interés puede redirigir recur: financieros desde reservas productos básicos hacia otr activos monetarios o financier

Desde este ángulo el caráct fluctuante de las tasas de inter y los tipos de cambio, tambi pueden ser considerados co condición importante, de los $p$ cesos de desregulación de la nomía mundial que se han pr pitado a partir de los años och ta y de la creciente inestabili 
Cuadro 3

Pagos del Servicio de la Deuda Externa Total (Millones de dólares)

\begin{tabular}{lrrrrrr}
\hline & 1988 & 1989 & 1990 & 1991 & 1992 & 1993 \\
\hline México & 15.472 & 15.562 & 11.453 & 13.705 & 20.705 & 17.1 \\
Perú & 348 & 497 & 476 & 1.153 & 1.032 & 2.4 \\
América Latina & 54.944 & 50.669 & 44.513 & 45.076 & 53.250 & 56. \\
\hline
\end{tabular}

Fuente.- Ibid. p. 286

\section{Cuadro 4}

Pagos al Exterior por Renta de Inversiones (Millones de dólares)

\begin{tabular}{lrrrrrr}
\hline & 1988 & 1989 & 1990 & 1991 & \multicolumn{1}{c}{1992} & 1993 \\
\hline México & 7.262 & 7.892 & 7.905 & 7.070 & 7.046 & 8.7 \\
Perú & 982 & 924 & 1.014 & 1.011 & 959 & 9 \\
América Latina & 35.097 & 39.011 & 33.979 & 30.733 & 28.756 & 30.7 \\
\hline
\end{tabular}

Fuente- Ibidem

en los precios de los productos básicos que se ha detectado en épocas recientes.

\section{LA GLOBALIZACION} COMO PROCESO DE MUNDIALIZACION DE LAS RELACIONES

III.1 Las economías nacionales totalmente integradas

La tendencia a la mundialización impone ahora una figura única, la de las economías nacionales totalmente integradas por distintos conceptos en el sistema económico mundial, lo que ha venido a denominarse globalización. Los modelos de economía "abierta" consideran la apertura exclusivamente en términos de relaciones comerciales con el exterior. Ahora bien, un enfoque más objetivo de las economías nacionales implica tener en cuenta no solamente flujos de comercio y de inversión extranjera, sino el conjunto de determinaciones que lleva consigo la mundialización del espacio capitalista respecto a la economía nacional. Es decir, en nuevo problema planteado a la economía contemporánea es desarrollar un enfoqueglobalizador, que pueda dar parte del grado y formas de integración de una determinada economía nacional en el sistema económico mundial.
El importante crecimiento del comercio internacional desde fines de los años cincuenta favoreció una división internacionaldel trabajo cada vez más marcada en la industria y, en menor grado, en la agricultura y los servicios. En primer lugar, en nuestros países la industrialización es por definición una especialización,en la medida que durante un largo tiempo abarcó a un sector limitado, e.g., las industrias de consumo en oposición a las industrias de bienes de capital en general, intensivas en trabajo o intensivas en materias primas. En segundo lugar, en los países desarrollados, el intercambio e inversiones internacionales han engendrado especializaciones en una $u$ otra rama de la industria o en diferentes tipos de productos, según hayan sido las políticas de los Estados, las estrategias de las empresas, la índole de los mercados de trabajo y la actitud de los sindicatos. Los aparatos productivos nacionales han tenido tendencias a reorganizarse sobre una base internacional, constituyendo un auténtico sistema productivo mundial.

Esta mundialización del sistema productivo, sobre todo industrial, incide muy claramente en las condiciones de producción y de circulación de la tecnología a escala internacional. Tiende a concentrar el acondicionamiento de las innovaciones técnicas a gran escala en aquellos países que dominan la concepción y fabricación de equipos de los que dependen el conjuntodeindustrias, es decir, los bienes de capital que sirven para la fabricación de otros equipos. La participación de un país en la creación tecnológica suele condicionarse mucho al lugar que ocupa y conserva en la jerarquía industrial mundial.

El reciente desarrollo de las nuevas tecnologías (informática, robótica, microelectrónica, nuevos materiales, biotecnologías, etc.) fortalece la tendencia a la constitución de un sistema mundial jerarquizado de producción de tecnológica; estrechamente vinculadas a los avances del conocimiento científico, estas tecnologías nuevas dependen de inversiones de gran magnitud en la investigación, que se concentran en los grandes países desarrollados. Estas tecnologías llevan consigo la creación de nuevas ramas de actividad, como la industria de semiconductores, que son casi siempre patrimonio de los países desarrollados. Tienden simultáneamente a modificar la estructura técnica de todas las industrias, concentrando así en un reducido número de países y transnacionales la capacidad de remodelar el perfil tecnológico de la industria mundial.

Estos enfoques contradicen las recomendaciones de los teóricos neoliberales para la liberalización completa del comercio y de la inversión extranjera en nuestros países, como en los programas de ajuste estructural del Fondo Monetario, en ambos se encierra una profunda contradicción. No se puede, por ejemplo, preconizar un desarme aduanero total (y por consiguiente la ausencia de compromiso del Estado) y refe- 
rirse al mismo tiempo de la necesidad de fomentar las exportaciones industriales. La supresión totalde la protección externaafecta a las condiciones de rentabilidad de una gama amplia de industrias, entre ellas las industrias que podrían transformarse en exportadoras si tuvieran un apoyo estatal.

Por lo demás, no puede considerarse que la liberalización del comercio exterior, de la inversión extranjera y de los sistemas cambiarios en el marco de los programas de ajuste estructural de los países subdesarrollados hayan propiciado realmente una mayor apertura a la economía mundial. En América Latina, la aplicación de estos programas ha tenido como resultado el mantenimiento a su nivel precedente del grado de apertura de la economía nacional; medido por la relación entre las exportacionese importaciones del producto bruto interno.

\section{LOS NUEVOS CAMPOS DE INVESTIGACION}

IV.1 La política económica como objeto de investigación prioritaria

Cuando la investigación en nuestros países se interesa en la política económica, se limita frecuentemente a enfoques parciales centrados en sectores de actividad particulares, dejando de lado la comprensión global de las estrategias estatales, o puede limitarse igualmente a realizar enfoques meramente descriptivos. El retraso de la investigación en términos de medios materiales, humanos y organizativos se ha agravado en este caso por causa de la desconfianza que siempre mostraron los regímenes, en general nada democráticos, hacia el análisis y la reflexión independientes aplicadas a las políticas del Estado.

Se dice que la política es el arte de lo posible. ¿Cómo identificar, precisamente, los límites del campode posibilidades? ¿Cómo evaluar el grado de libertad de la política económica, es decir, su capacidad de remodelar las estructuras sociales y económicas? ¿Cuál es por otra parte, el proyecto nacional que expresa una política económica y quiénes son los protagonistas?, por último, ¿Cuáles son los instrumentos de los que disponen o podrían disponer los gobiernos para sus políticas económicas?. Estos son los principales cuestionamientos a los cuales los distintos especialistas de las ciencias sociales deben ahora intentar dar respuesta, a la

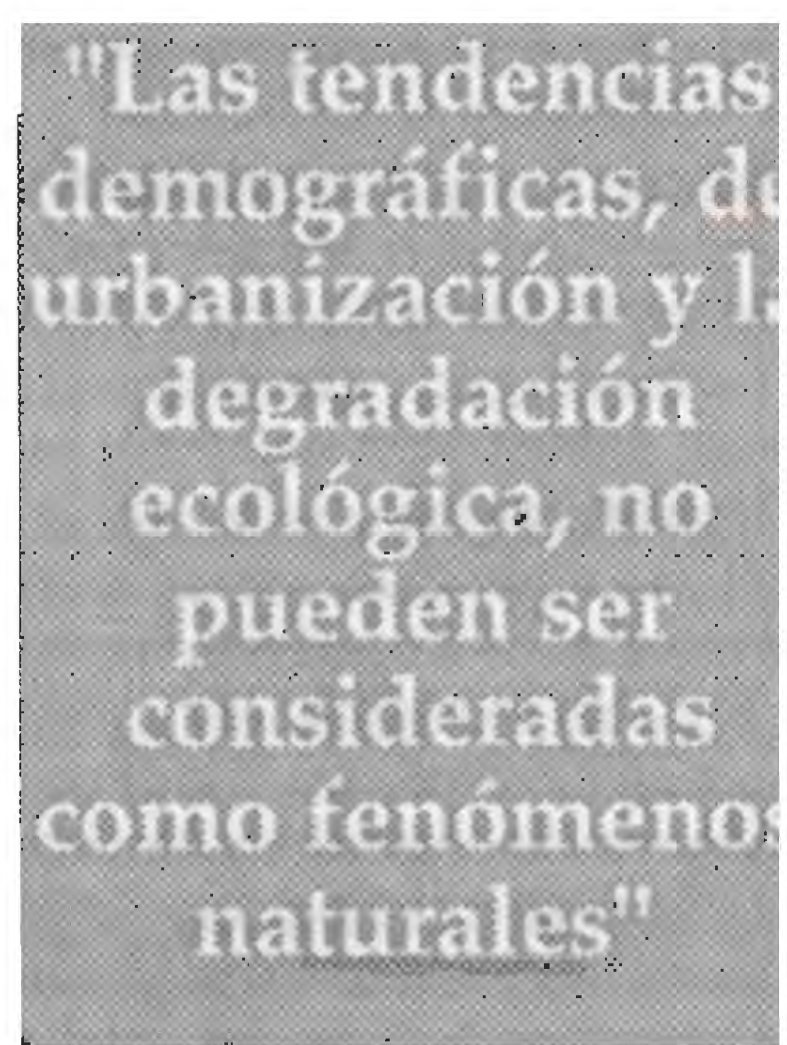

luz de la evolución reciente del sistema económico internacional, y de las nuevas condiciones de funcionamiento que tal evolución implica para las economías nacionales de lo distintos países. Estos cuestionamientos tienen rasgos nuevos por las mutaciones cada vez más profundas del sistema mundial.

IV.2 ¿Cómo evaluar el impacto de la política económica?

Para un país subdesarrollado, los socks externos, como la baja de precios o la demanda de materias primas; la baja o el alza de los precios del petróleo (según se trate de países exportadores de ener- gía o no), la reducción de las inversiones extranjeras, el alza de las tasas de interés, las fluctuaciones del dólar y el proteccionismo de los países desarrollados juegan un papel de primera importancia en la evolución económica y social, en particular, en la agravación de la crisis a partir de fines de los años setenta. Crisis resultante al mismo tiempo de la acción de fenómenos de largo plazo, como el crecimiento demográfico, los niveles de analfabetismo y la masiva migración del campo a la ciudad. El conjunto de estos fenómenos ejercen su impacto de forma irresistible y marcan rigurosos límites a la acción gubernamental. El margen de libertad que deja la combinación de estos factores externos y delas presiones internas es, pues, en este caso, infinitamente más estrecho.

En perspectiva, los fenómenos de larga duración, lo mismo que las presiones del entorno internacional, pueden considerarse (parcialmente) en variables de la política económica de los Estados. El impacto de los cambios internacionales es más o menos importante según el grado y formas de dependencia externa del país; los cuales son en última instancia, resultadode una dialéctica compleja entre las políticas aplicadas y la materia económica y social sobre la que actúan. En cuanto a las tendencias demográficas, de urbanización y la degradación ecológica, no pueden ser consideradas como fenómenos naturales, porque manifiestan rupturas de equilibrios entrelos individuos y los grupos, por una parte, y los recursos y el medio de otra; a veces esas rupturas proceden del impacto de las políticas del pasado. No obstante, el horizonte tem poral de la política económica es el corto y mediano plazo, y desde este punto de vista los elementos que han dado su textura actual al tejido 
económico y social se imponen como variables independientes.

Las políticas económicas en nuestros países conocen un margen de libertad tan estrecho que cuando por ejemplo, se intenta medir la acción gubernamental en función de la transformación de las estructuras económicas de un país, se presentan con frecuencia dificultades en el momento de disociar la política del Estado de la evolución "natural" de la economía y de la sociedad y las desgarradoras revisiones que a veces aparecen en los documentos programáticos oficiales.

Del mismo modo, en nuestros países se puede observaruna sorprendente convergencia de los problemas económicos y sociales entre países cuyas políticas gubernamentales tenían fama de ser más bien divergentes. Se trata de un problema cuyo tratamiento no puede aplazarse indefinidamente, sobre todo porque con la democratización de los regímenes políticos está tomandouna nueva dimensión, que reduce a priori la autonomía del poder político en relación a la sociedad, y por lo tanto, al margen de maniobra del Estado en la transformación de las estructuras económicas y sociales.

IV. 3 El contenido social de la política económica.

Una mala política económica no se explica siempre por un conocimiento insuficiente de los mecanismos de la economía o por una mala evaluación de las condiciones económicas, aún cuando estos elementos no sean nada desdeñables. Una política económica inoperante, por ejemplo desde el punto de vista de la autonomía nacional, de la expansión del producto o de la elevación del nivel de vida, puede haber incumplido tales objetivos por causa de errores cometidos por las autoridades. Pero tam- bién es posible que los objetivos perseguidos oficialmente no hayan coincidido con los intereses fundamentales de las capas dirigentes.

Apoyándose en elementosque el discurso de los Estados ponía de relieve, se nos ha conducido a menudo a ver políticas de desarrollo, cuando en realidad las estrategias estatales se reducían a simples políticas sectoriales sin la articulación a un proyecto global de transformación positiva de la economía y de la sociedad. El debate de los modelos, tipos o estilos de desarrollo se realizó más en términos ideológicos que cientificos $y$, si ahora podemos afirmar que las políticas económicas aplicadas han fracasado, no es posible deducir, que han fracasado los modelos de desarrollo, porque su esencia nunca fue definida ni su aplicación concretamente estudiada. Es por lo tanto urgente hacer un análisis de las políticas económicas efectivamente puestas en práctica, identificar el proyecto socialque promueven, disponerlas en función de su impacto sobre los grupos sociales presentes y aclarar sus relaciones con las estrategias de los actores exógenos.

El afán de los gobiernos por

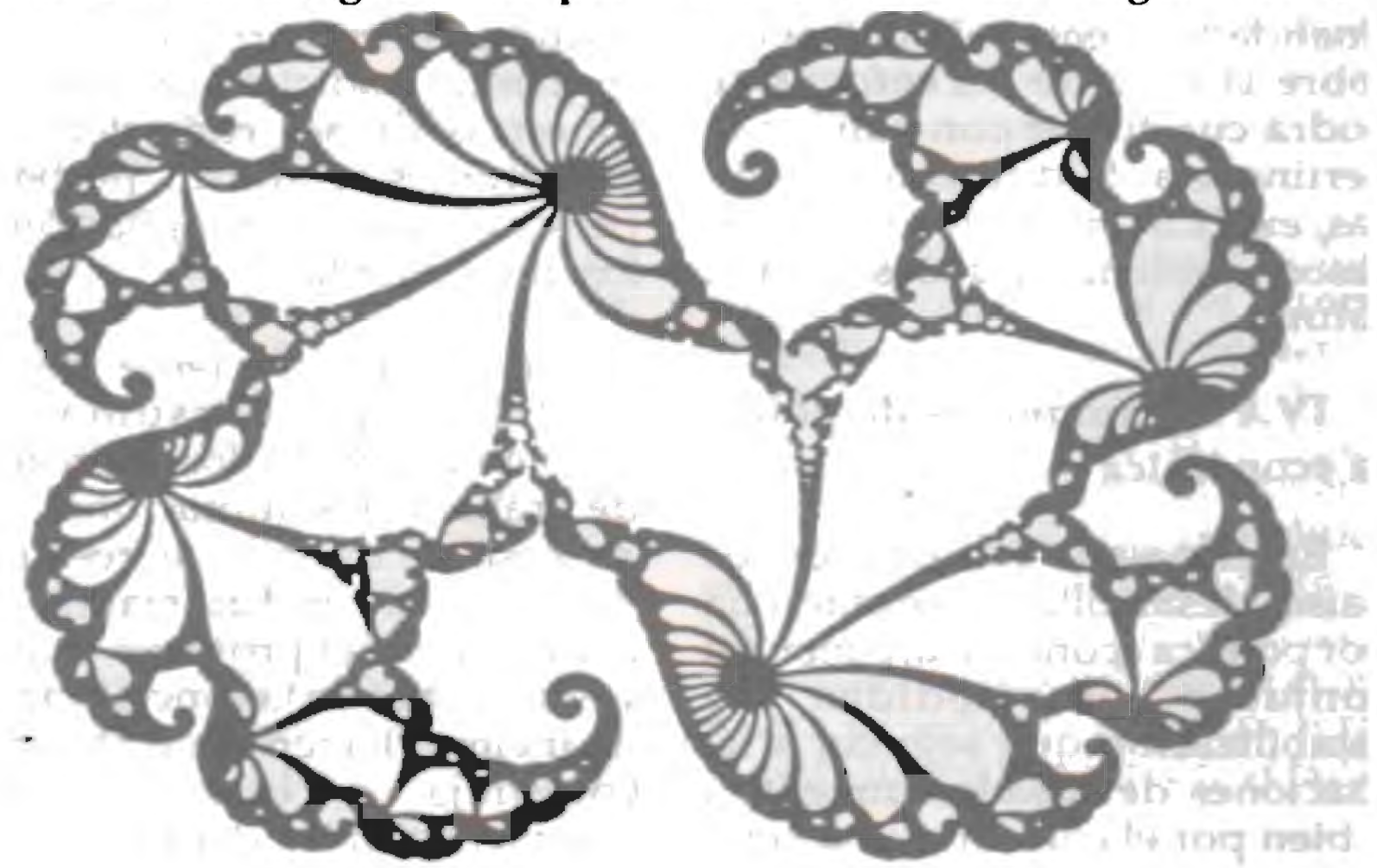

desalentar la reflexión crítica en torno a sus políticas, hizo que se considerara sospechoso cualquier esfuerzo de análisis global. De este modo, se cultivó una tendencia anti-teoría sobre la base que la urgencia de los problemas del desarrollo no podía autorizar "el lujo" de la reflexión teórica. Así un director de un centro de investigación, podía por ejemplo declarar que era preferible para su país que los investigadores reflexionaran sobre los medios de abastecer los mercados de frutas y legumbres, que en la evolución de la economía internacional o en la teoría del capital y del progreso técnico. Con enfoques de este tipo se logra culpar a los teóricos y precipitar a la mayoría de los investigadores en tareas de horizonte estrecho y de óptica puramente instrumental, centrados sobre uno u otro aspecto sectorial de la política estatal y de la evolución de la economía. En cambio, la tendencia a la continuidad democrática en nuestros países, crea las condiciones para una investigación más autónoma sobre los gobiernos y también un ambiente más favorable a la eliminación deciertos tabúes.

Por cierto, la quiebra casi general de las políticas de desarrollo han llevado a los gobiernos como a los investigadores a 


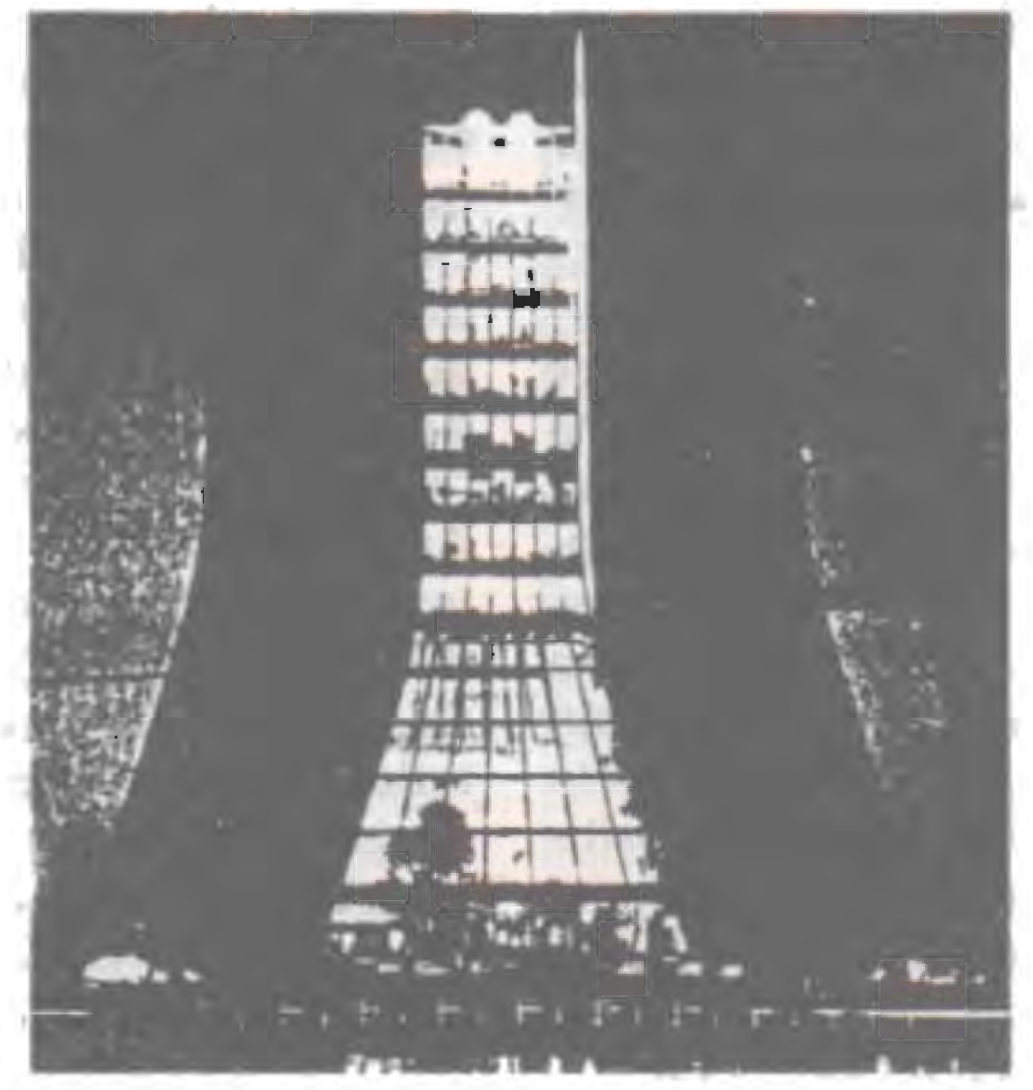

relativizar su desdén por la teoría y a volver a poner en tela de juicio la supuesta eficacia de una investigación puramente instrumental. Y puede observarse hasta qué punto es cierto aquello de existe una buena investigación aplicada sin una reflexión global y sin el enfoque científico que sólo una buena formación teórica puede garantizar.

En adelante, es menester despejar la incógnita, a partir de un tratamiento sistemático y comparativo de las experiencias nacionales concretas, de la naturaleza y significación de las políticas económicas, distinguir entre sus objetivos proclamados y sus finalidades reales. Unicamente sobre la base de tal enfoque se podrá cuestionar con validez la pertinencia de diferentes políticas, explicar sus éxitos y sus fracasos y obtener indicios para el futuro.

\section{IV.4 Instrumentos de políti- ca económica}

En el pasado reciente, en los países desarrollados se entendía por política económica, o bien un conjunto de medidas de estabilización que seguían a situaciones de "recalentamiento", o bien por el contrario una serie multáneamente, la internacionalización cada vez más marcada de los mercados de bienes, de servicios y capitales, y el destacado papel de los mercados de las empresas transnacionales y de los bancos multinacionales redujeron sensiblemente la capacidad del Estado para remodelar las condiciones económicas y sociales de la nación. Salvo en el caso de los países dominantes, la política económica de un Estado depende, en mayor o menor grado, de la de sus socios extranjeros más importantes.

Las nuevas políticas económicas ya no consisten en actuar sólo sobre los grandes equilibrios macroecómicos, sino en transformar los aparatos productivos nacionales y en desarrollar las capacidades tecnológicas del país, con miras de defender y mejorar su situación competitiva en el mercado internacional. Tales políticas-industrial, agrícola, de formación profesional y de investigación- tienen por objeto la reasignación de los recursos productivos y no solamente el manejo de la economía. Implican, además, en la mayoría de los casos, la utilización simultánea de esos nuevos instrumentos y de los convencionales.

Existe aquí igualmente un nuevo campo para la reflexión y el análisis. Se trata por una parte. de repensar de nuevo en el manejo de los instrumentos tradicionales de intervención estatal, sean de inspiración keynesiana o neoclásica, sobre todo cuando se aplican, como ocurre ahora a menudo, en coordinación con otros países en la fijación de las tasa de interés y los tipos de cambio y, por otra parte, de estudiar los instrumentos nuevos, como los programas sectoriales $d$ reconversión y de reestructuración industriales, los sistemas d ayuda y de apoyo a la agricultu- 
ria. Teniendo en cuenta el papel por lo general más amplio que juega el Estado en nuestros países, la política económica debería constituir una de las primeras metas de la formación superior.

Debería concederse, además, atención particular a la formación de especialistas en el campo de la finanzas, debido a los efectos de la desregulación financiera y monetaria mundial y la incertidumbre creciente del entorno internacional.
3. La crítica científica del discurso de los gobiernos sobre su práctica económica sirve objetivamente a los intereses del conjunto de la sociedad y permite a los actores sociales, en particular cuando no están representados en los aparatos del poder, disponer de los medios intelectuales necesarios para la defensa de sus intereses $\mathrm{y}$, aún más, para la formulación de políticas alternativas.

Las cuestiones que se plantean a la reflexión y a la investiga- ción se dirigen igualmente a los sistemas de formación universitaria, en los países subdesarrollados todavía más que en los países desarrollados. Las exigencias de una apolítica económica más racional y más eficaz, desde el punto de vista de los intereses de la mayoría de la población, sitúa ahora en primer plano el imperativo de la formación de especialistas, capacitados para una comprensión crítica de las políticas económicas como para el dominio de los instrumentos de dichas políticas.

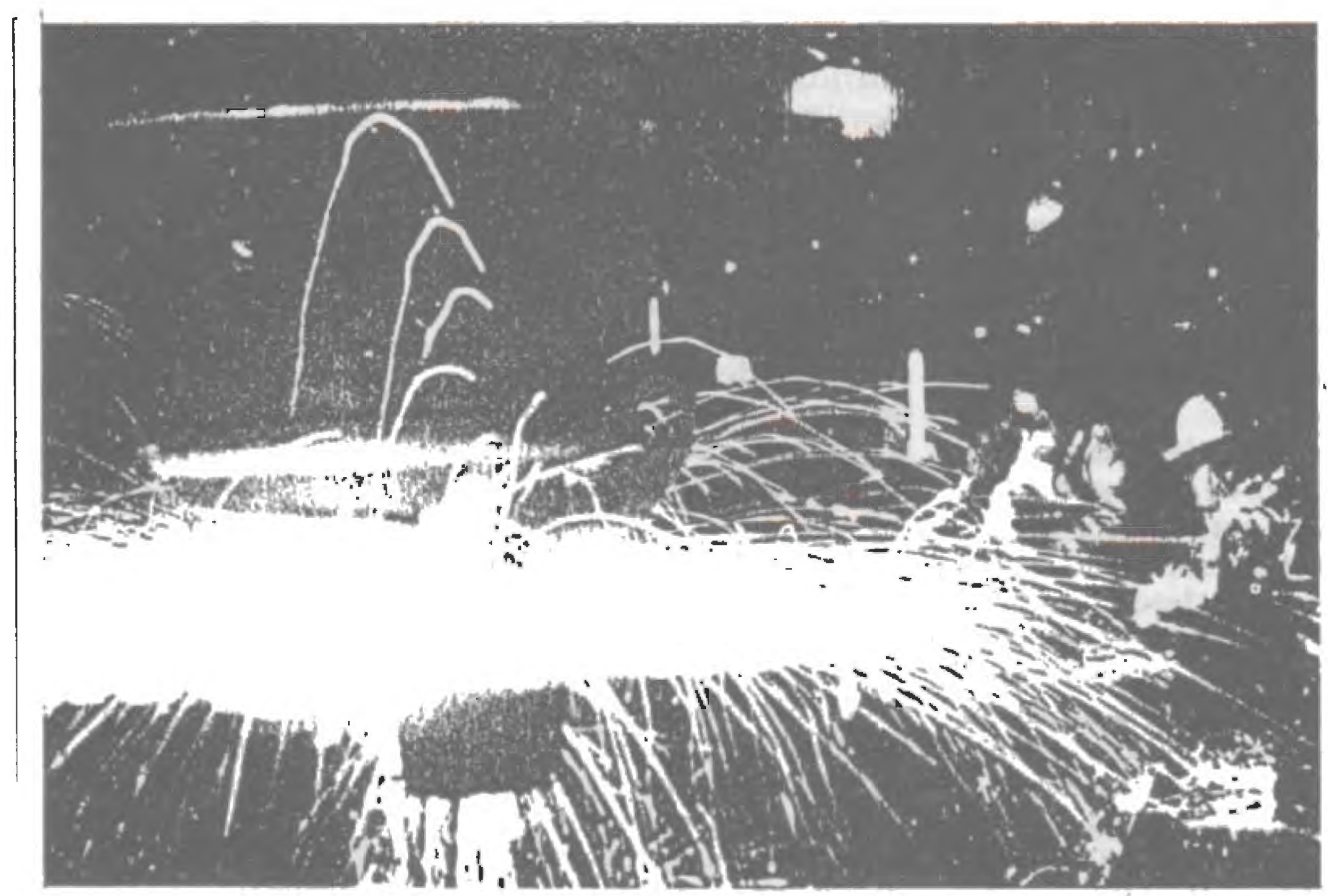

